\title{
Ambulatory blood pressure of adults in Novosibirsk, Russia: interim report on a population study Tatiana Kuznetsovaa,b, Sofia Malyutina ${ }^{a}$, Elena Pello ${ }^{a}$, Lutgarde Thijs ${ }^{b}$, Yuri Nikitin ${ }^{\mathrm{a}}$ and Jan A. Staessen ${ }^{\mathrm{b}}$
}

Objective To describe the distributions of the ambulatory blood pressure in a sample drawn from the Siberian population.

Methods In the European Project On Genes in Hypertension (EPOGH), a random population sample of 162 persons (72 men and 90 women) was investigated in Novosibirsk, Russia. Mean age $( \pm S D)$ was $40.6 \pm$ 15.3 years. Validated oscillometric 90207 SpaceLabs monitors were programmed to obtain ambulatory blood pressure readings at intervals of $15 \mathrm{~min}$ from $0800 \mathrm{~h}$ to $2200 \mathrm{~h}$ and at $30 \mathrm{~min}$ intervals from $2200 \mathrm{~h}$ to $0800 \mathrm{~h}$. Daytime and nighttime were defined using short fixed-clock time intervals, which ranged from $1000 \mathrm{~h}$ to $2000 \mathrm{~h}$ and from midnight to $0600 \mathrm{~h}$, respectively.

Results In the 162 participants, of whom 54 were hypertensive, 24-h clocktime day and clocktime night blood pressures averaged 120/73, 126/79 and 110/ $60 \mathrm{mmHg}$, respectively. Compared with daytime values, blood pressures at the clinic were $5.7 / 1.1 \mathrm{mmHg}$ lower in 108 normotensive people, but $17.0 / 13.1 \mathrm{mmHg}$ higher in 54 hypertensive patients. In the normotensive subgroup, the 95th percentiles of the 24-h clocktime day and clocktime night blood pressures were 128/81, $136 / 86$ and $118 / 72 \mathrm{mmHg}$, respectively.

Conclusion In comparison with other population surveys, the present interim report on the EPOGH study produced consistent results with respect to the distributions of the ambulatory measurements both in normotensive subjects and in the overall study population. Blood Press Monit 5:291-296 (c) 2000 Lippincott Williams \& Wilkins.

Blood Pressure Monitoring 2000, 5:291-296

Keywords: ambulatory blood pressure, clinic blood pressure, conventional sphygmomanometry, population

${ }^{a}$ Institute of Internal Medicine, Siberian Branch of the Russian Academy of Medical Sciences, Novosibirsk, Russia; ${ }^{b}$ Study Coordinating Centre, Hypertension and Cardiovascular Rehabilitation Unit, Department of Molecular and Cardiovascular Research, University of Leuven, Leuven, Belgium.

Correspondence and requests for reprints to Jan A. Staessen, MD, PhD, Studiecoordinatiecentrum, Laboratorium Hypertensie, Campus

Gasthuisberg, Herestraat 49, B-3000 Leuven, Belgium. Tel: +32 1634 7104 (office) or +32 15411747 (home); fax: +32 16 347106 (office) or +3216345763 (office) or +3215414542 (home);

e-mail: jan.staessen@med.kuleuven.ac.be

Received 08 September 2000 Accepted 25 October 2000

\section{Introduction}

The distribution of the ambulatory blood pressure must be better characterized in various conditions and populations and compared with conventional blood pressure measurements. Along these lines, several large-scale epidemiological studies in well-defined professional groups $[1,2]$, in normotensive and hypertensive subjects [3-6] and in the population at large [7-15] have recently been completed. In an attempt to describe the distribution of the ambulatory blood pressure and to determine operational thresholds for ambulatory blood pressure monitoring, the 24-h blood pressure was recorded in a random sample drawn from the population of Novosibirsk, Russia.

\section{Methods}

Study population

In this population survey, the participants (minimum age 18 years) were randomly selected from the inhabitants of the Oktyabrsky district of Novosibirsk city. The sample comprised 200 subjects (response rate 66\%). At the time of writing of this report, 165 of the participants had undergone ambulatory blood pressure measurement and were included in the analysis.

\section{Auscultatory blood pressure readings}

The subjects enrolled in this study were invited for technical examinations at a locally organized clinic. A self-administered questionnaire was employed to inquire into each participant's medical history, smoking habits, alcohol consumption and intake of medications. The participants were seated and asked to relax for $5 \mathrm{~min}$. The observers measured the subjects' sitting blood pressure five times consecutively. In most subjects standard cuffs were used, which had an inflatable bladder with a length of $22 \mathrm{~cm}$ and a width of $12 \mathrm{~cm}$. If arm circumference exceeded $31 \mathrm{~cm}$, larger cuffs with $35 \times 15 \mathrm{~cm}$ bladder were employed. The guidelines of the British Hypertension Society were followed [16]. Systolic and diastolic (phase V) pressures were determined to the nearest $2 \mathrm{mmHg}$. For analysis, the five readings of the clinic visit were averaged.

In agreement with current medical practice, normotension and hypertension were defined solely on the basis of traditional sphygmomanometry [17,18]. Normotension was defined as a conventional blood pressure not 
higher than $139 \mathrm{mmHg}$ systolic and $89 \mathrm{mmHg}$ diastolic. Definite (moderate or severe) hypertension was present if the conventional blood pressure readings exceeded $160 \mathrm{mmHg}$ systolic or $95 \mathrm{mmHg}$ diastolic, or when the patients were on antihypertensive medication regardless of their actual blood pressure. Untreated subjects, whose conventional blood pressure ranged from 140 to $159 \mathrm{mmHg}$ systolic or from 90 to $94 \mathrm{mmHg}$ diastolic, were considered to have mild (borderline) hypertension.

The observers involved in this report $(n=2)$ were tested for the accuracy of their blood pressure measurements at 3-month intervals. Digit preference was checked at 6-month intervals.

\section{Ambulatory blood pressure measurement}

The ambulatory measurements were obtained with oscillometric SpaceLabs 90202 monitors (SpaceLabs Inc., Redmond, Washington, USA) [19,20]. The calibration of these devices was checked monthly against a mercury column. The recorders were programmed to obtain measurements with an interval of $15 \mathrm{~min}$ from $0800 \mathrm{~h}$ until $2200 \mathrm{~h}$ and every $30 \mathrm{~min}$ from $2200 \mathrm{~h}$ to $0800 \mathrm{~h}$.

If the ambulatory recordings were longer than $24 \mathrm{~h}$, only the first $24 \mathrm{~h}$ were used for analysis. Intra-individual means of the ambulatory measurements were weighted by the time interval between successive readings [21]. In keeping with current recommendations [22], daytime was defined as the interval from $1000 \mathrm{~h}$ to $2000 \mathrm{~h}$ and nighttime from midnight to $0600 \mathrm{~h}$. These definitions have been used in previous publications [10,21] and eliminate the transition periods in the morning and the evening during which the blood pressure changes rapidly in most subjects.

Three subjects were removed from the analysis, because their ambulatory recording covered less than $20 \mathrm{~h}$, or because less than 10 readings were available for the computation of the daytime blood pressure or less than 5 for the blood pressure at night.

\section{Statistical analysis}

Database management and statistical analyses were performed with SAS software, version 6.12 (SAS Institute Inc., Cary, North Carolina, USA). The central tendency and the spread of the data are reported as the mean \pm SD. Departure from normality was evaluated by Shapiro-Wilk's statistic [23] and skewness by the computation of the coefficient of skewness, i.e. the third moment about the mean divided by the cube of the standard deviation [24]. The normal distribution was used to determine the significance of the coefficient of skewness [24].

The methods of analysis included Student's $t$-test, the $\chi^{2}$ statistic, and simple and multiple regression [25]. Multivariate analysis of variance was performed to test the null hypothesis of no differences between the parameters of regression equations [25,26]. The discrepancy between the daytime ambulatory measurements and the conventional blood pressure readings at the clinic was investigated by the methods proposed by Gould [27]. For each comparison, the mean discrepancy and the standard deviation of the individual differences were calculated.

\section{Results}

\section{Characteristics of the population}

The participants, 72 men and 90 women, were $40.6 \pm 15$ years old (mean $\pm \mathrm{SD}$; range $18-76$ years). Body weight in the 72 men averaged $75.3 \pm 12.8 \mathrm{~kg}$, body mass index $24.5 \pm 3.7 \mathrm{~kg} / \mathrm{m}^{2}$, and circumference of the upper arm $29.0 \pm 2.6 \mathrm{~cm}$ (range $24.0-37.0 \mathrm{~cm}$ ); in women these values were $69.2 \pm 12.2 \mathrm{~kg}, 26.3 \pm 5.7 \mathrm{~kg} / \mathrm{m}^{2}$, and 28.6 $\pm 4.2 \mathrm{~cm}(20.0-38.0 \mathrm{~cm})$, respectively.

Of the 162 participants, $46(28.4 \%, 36$ men and 10 women) were smokers; 4 women $(12.3 \%$ of those aged 55 years or younger) took the contraceptive pill.

\section{Ambulatory measurements}

In all subjects the distribution of the 24-h systolic blood pressure departed from normality $(P<0.01$; Fig. 1$)$ and was positively skewed $(P<0.001)$; the coefficient of skewness was 0.44 . The distribution of the 24 -h diastolic blood pressure was close to normality $(P=0.1$; Fig. 1); the coefficient of skewness was 0.25 .

Fig. 1

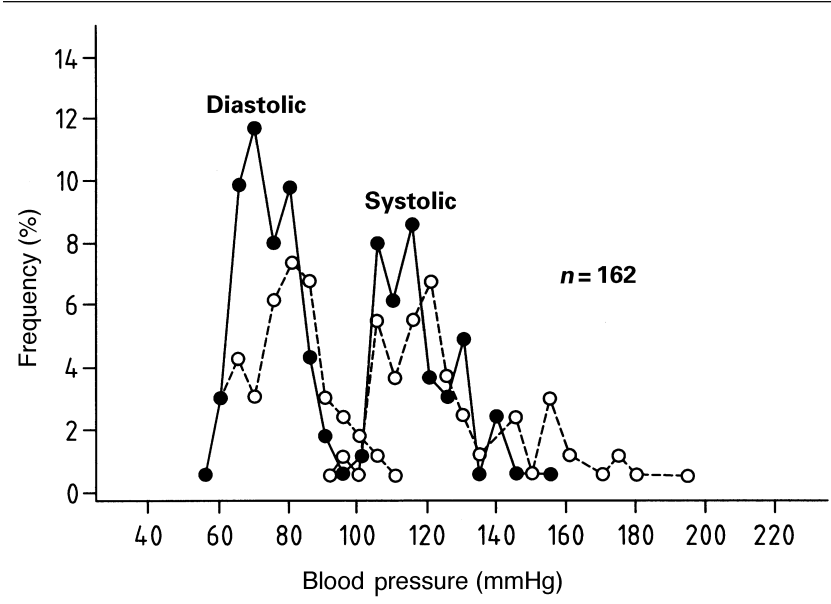

The distribution of the systolic and diastolic blood pressures in 162 individuals drawn at random from the general population. $\bullet, 24-\mathrm{h}$ ambulatory blood pressure; $\circ$, conventional blood pressure measured at the clinic. 
Fig. 2

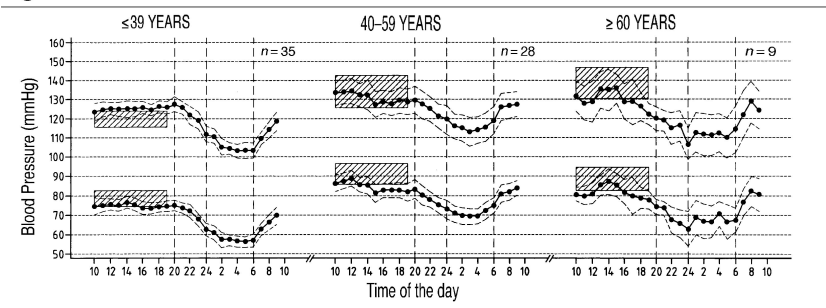

Ambulatory systolic (upper curves) and diastolic (lower curves) blood pressures in men in three age categories. The hourly means with 95\% confidence interval are presented. The shaded bands indicate the $95 \%$ confidence interval for the clinic blood pressure measurements (five readings in the sitting position).

In all participants combined, the 24-h ambulatory blood pressures averaged $119.8 \mathrm{mmHg}$ systolic and $73.2 \mathrm{mmHg}$ diastolic [95\% confidence intervals (CI) 118.0-121.6 and $72.0-74.5 \mathrm{mmHg}$. The daytime blood pressures averaged 125.6 and $78.7 \mathrm{mmHg}$ (CI 123.8-127.4 and $77.5-79.9 \mathrm{mmHg}$ ) and the nighttime pressures were 110.2 and $64.2 \mathrm{mmHg}$ (CI $108.0-112.3$ and $62.7-$ $65.7 \mathrm{mmHg}$ ). The average blood pressures and corresponding 95\% CI for any hour during the day are presented for men and women in three age groups ( $\leq 39,40-59$ and $\geq 60$ years) in Figure 2 and Figure 3 .

The hourly means with $95 \%$ confidence interval are presented. The shaded bands indicate the $95 \%$ confidence interval for the clinic blood pressure measurements (five readings in the sitting position).

A total of $54(33.3 \%)$ participants were hypertensive, because their conventional blood pressure measured at the clinic exceeded the limits of $139 \mathrm{mmHg}$ systolic or $89 \mathrm{mmHg}$ diastolic $(n=34 ; 63.0 \%)$ or because they were on treatment with antihypertensive drugs $(n=20$; $37.0 \%$ ). Of these 54 patients, 10 were only borderline hypertensive and 44 had definite hypertension.

In the 108 normotensive people, the 24 -h blood pressures averaged $114.5 \mathrm{mmHg}$ systolic and $69.7 \mathrm{mmHg}$ diastolic (CI 112.9-116.1 and 68.6-70.9 mmHg). The daytime blood pressures in the normotensive subjects were 120.8 and $75.7 \mathrm{mmHg}$ (CI 119.0-122.6 and $74.5-77.0 \mathrm{mmHg}$ ) and the blood pressures at night were 104.4 and $60.1 \mathrm{mmHg}$ (CI 102.7-106.1 and 58.8$61.4 \mathrm{mmHg}$ ). Additional statistics of the ambulatory blood pressures are presented for normotensive men and women and two age groups $(\leq 39, \geq 40$ years) separately in Table 1 .

\section{Clinic versus ambulatory measurements}

In the total study sample $(n=162)$, the blood pressures at the clinic averaged $127.4 \mathrm{mmHg}$ systolic and
83.0 $\mathrm{mmHg}$ diastolic (CI 124.1-130.8 and 80.9-85.1 $\mathrm{mmHg}$ ). The $95 \%$ CI of the average blood pressures obtained at the clinic visit in the six subgroups by sex and age are shown in Figure 2 and Figure 3 (hatched area).

In the total study sample $(n=162)$, systolic blood pressure at the clinic was $1.9 \pm 16.2 \mathrm{mmHg}$ higher $(P<0.001)$ than the daytime systolic blood pressure (CI $0.6-4.4 \mathrm{mmHg}$ ); for diastolic blood pressure the corresponding difference between the clinic and daytime pressures averaged $4.3 \pm 10.4 \mathrm{mmHg}$ (CI $2.7-5.9 \mathrm{mmHg} ; P<0.001)$. The blood pressures at the clinic were considerably higher $(P<0.001)$ than the 24-h blood pressures, as the latter included both the daytime and the low nighttime values.

In the 108 normotensive subjects, the systolic and diastolic blood pressures at clinic averaged $115.1 \mathrm{mmHg}$ (CI $113.3-116.9 \mathrm{mmHg}$ ) and $75.6 \mathrm{mmHg}$ (CI $74.2-$ $77.1 \mathrm{mmHg}$ ), respectively. In the normotensive subjects, systolic and diastolic blood pressures measured at the clinic were on average $5.7 \pm 9.9 \mathrm{mmHg}$ (CI 3.9$7.6 \mathrm{mmHg} ; P<0.001)$ and $0.1 \pm 8.0 \mathrm{mmHg}(\mathrm{CI}-1.4$ to $1.6 \mathrm{mmHg}$ ) lower than the corresponding daytime blood pressures.

In contrast to the normotensive people, the 54 hypertensive patients had mean clinic blood pressures which were higher than daytime ambulatory measurements $(P<0.001)$. Compared with the latter values, the hypertensives' blood pressures at the clinic were systolic $17.1 \mathrm{mmHg}$ (CI $12.8-21.3 \mathrm{mmHg}$ ) and diastolic $13.1 \mathrm{mmHg}$ (CI 10.6-15.5 mmHg) more elevated.

\section{Age as blood pressure determinant}

There was a curvilinear association between the clinic and the 24-h blood pressures and age (Figure 4). A regression model, including age and age-squared, was therefore required to describe these relations in men and women. In men, age explained $19.2 \%$ of the variance of systolic pressure at the clinic and $17.2 \%$ of the variability of the corresponding diastolic pressure. In

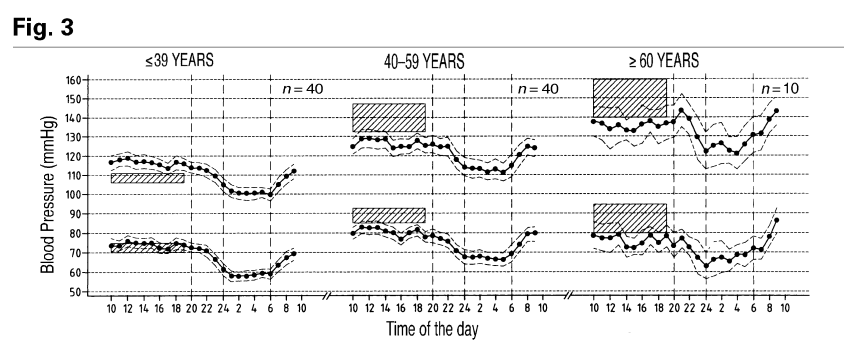

Ambulatory systolic (upper curves) and diastolic (lower curves) blood pressures in women in three age categories. 
Table 1 Systolic-diastolic blood pressures $(\mathrm{mm} \mathrm{Hg})$ in 108 subjects who were randomly selected from the population and who were normotensive at the clinic visit

\begin{tabular}{|c|c|c|c|c|c|c|c|}
\hline & \multicolumn{3}{|c|}{ Men } & \multicolumn{3}{|c|}{ Women } & \multirow[t]{2}{*}{ Both sexes } \\
\hline & $<40$ years & $\geq 40$ years & All men & $<40$ years & $\geq 40$ years & All women & \\
\hline $\begin{array}{l}\text { Number } \\
\text { Clinic blood pressure }\end{array}$ & 32 & 18 & 50 & 39 & 19 & 58 & 108 \\
\hline Mean & $118 / 76$ & $119 / 80$ & $118 / 78$ & $109 / 72$ & $120 / 78$ & $112 / 74$ & $115 / 76$ \\
\hline SD & $9 / 8$ & $7 / 5$ & $9 / 7$ & $8 / 8$ & $8 / 5$ & $10 / 8$ & $10 / 8$ \\
\hline P5 & $103 / 61$ & $103 / 69$ & $103 / 66$ & $94 / 61$ & $108 / 69$ & $95 / 61$ & $99 / 62$ \\
\hline P50 & $117 / 77$ & $120 / 81$ & $118 / 79$ & $108 / 72$ & $119 / 79$ & $125 / 84$ & $128 / 85$ \\
\hline P90 & $131 / 86$ & $126 / 85$ & $129 / 86$ & $120 / 84$ & $133 / 86$ & $125 / 84$ & $128 / 85$ \\
\hline P95 & $135 / 87$ & $127 / 87$ & $131 / 87$ & $124 / 87$ & $138 / 88$ & $129 / 87$ & $131 / 87$ \\
\hline \multicolumn{8}{|l|}{ Daytime blood pressure } \\
\hline Mean & $125 / 75$ & $123 / 80$ & $124 / 76$ & $116 / 75$ & $120 / 77$ & $118 / 75$ & $121 / 76$ \\
\hline SD & $8 / 7$ & $14 / 7$ & $10 / 7$ & $8 / 6$ & $6 / 6$ & $8 / 6$ & $9 / 7$ \\
\hline P5 & $112 / 61$ & $107 / 68$ & $109 / 65$ & $102 / 64$ & $110 / 64$ & $104 / 64$ & $108 / 65$ \\
\hline P50 & $125 / 73$ & $118 / 79$ & $124 / 76$ & $116 / 74$ & $119 / 77$ & $119 / 75$ & $120 / 75$ \\
\hline $\mathrm{P} 90$ & $135 / 83$ & $145 / 89$ & $137 / 85$ & $129 / 83$ & $132 / 84$ & $129 / 83$ & $133 / 84$ \\
\hline P95 & $136 / 84$ & $150 / 90$ & $140 / 87$ & $132 / 86$ & $133 / 85$ & $132 / 85$ & $136 / 86$ \\
\hline \multicolumn{8}{|c|}{ Night-time blood pressure } \\
\hline Mean & $107 / 58$ & $106 / 65$ & $106 / 60$ & $102 / 59$ & $105 / 62$ & $103 / 60$ & $104 / 60$ \\
\hline SD & $9 / 7$ & $11 / 5$ & $9 / 7$ & $8 / 6$ & $9 / 9$ & $8 / 7$ & $9 / 7$ \\
\hline P5 & $94 / 48$ & $91 / 58$ & $94 / 50$ & $93 / 50$ & $84 / 45$ & $93 / 50$ & $93 / 50$ \\
\hline P50 & $109 / 57$ & $104 / 64$ & $107 / 60$ & $99 / 58$ & $106 / 63$ & $101 / 59$ & $103 / 59$ \\
\hline P90 & $117 / 68$ & $120 / 73$ & $117 / 71$ & $115 / 68$ & $117 / 72$ & $115 / 70$ & $117 / 71$ \\
\hline P95 & $120 / 72$ & $128 / 75$ & $120 / 72$ & $115 / 71$ & $122 / 77$ & $117 / 72$ & $118 / 72$ \\
\hline \multicolumn{8}{|c|}{ Whole day blood pressure } \\
\hline Mean & $118 / 68$ & $117 / 75$ & $118 / 70$ & $111 / 68$ & $115 / 71$ & $112 / 69$ & $115 / 70$ \\
\hline SD & $7 / 6$ & $12 / 6$ & $9 / 6$ & $7 / 6$ & $7 / 7$ & $7 / 6$ & $9 / 6$ \\
\hline P5 & $107 / 57$ & $102 / 67$ & $106 / 60$ & $100 / 59$ & $98 / 58$ & $100 / 59$ & $102 / 59$ \\
\hline P50 & $118 / 68$ & $114 / 74$ & $116 / 70$ & $110 / 68$ & $116 / 73$ & $112 / 69$ & $114 / 69$ \\
\hline P90 & $126 / 82$ & $139 / 82$ & $129 / 79$ & $121 / 76$ & $126 / 81$ & $121 / 79$ & $126 / 79$ \\
\hline P95 & $131 / 85$ & $140 / 85$ & $132 / 81$ & $125 / 81$ & $128 / 81$ & $126 / 81$ & $128 / 81$ \\
\hline
\end{tabular}

Normotension was defined as a systolic pressure $<140 \mathrm{mmHg}$ and a diastolic pressure $<90$ mmHg on conventional blood pressure measurement at the clinic (average of five readings in the sitting position). Daytime ranges from $1000 \mathrm{~h}$ to $2000 \mathrm{~h}$ and night-time from midnight to $0600 \mathrm{~h}$. ${ }^{\mathrm{a}} \mathrm{Blood}$ pressure readings obtained by conventional sphygmomanometry.

women, these percentages were $48.3 \%$ and $33.9 \%$, respectively $(P<0.001$ for all). For the 24 -h systolic and diastolic blood pressures, the variance attributable to age amounted, respectively, to $7.9 \%(P=0.02)$ and $30.8 \%(P<0.001)$ in men and to $36.6 \%(P<0.001)$ and $15.3 \%(P<0.001)$ in women. Thus, with the exception of diastolic blood pressure in men, the relations with age were weaker for the 24-h than for the clinic blood pressures (Fig. 4).

\section{Discussion}

In the present study a random population sample was examined. The response rate was $66 \%$. The ambulatory blood pressure in all participants aged 18-76 years averaged $120 / 73 \mathrm{mmHg}$ over the whole day, $126 / 79 \mathrm{mmHg}$ during daytime and $110 / 60 \mathrm{mmHg}$ at night.

In previous studies which recruited mainly healthy subjects or patients referred to specialized clinics to exclude the diagnosis of hypertension (for review, see [3]) the average systolic blood pressures over the whole day ranged from 111 to $124 \mathrm{mmHg}$, the daytime systolic pressure averages ranged from 115 to $128 \mathrm{mmHg}$ and the nighttime systolic means from 99 to $111 \mathrm{mmHg}$; the corresponding ranges for the diastolic blood pressure means embraced 59 and $79 \mathrm{mmHg}, 63$ and $85 \mathrm{mmHg}$ and 51 and $70 \mathrm{mmHg}$, respectively [3]. Furthermore, the means of the ambulatory measurements in the present study were almost identical to those noticed for the 24-h, daytime and nighttime blood pressures in a recent Belgian population study $(119 / 71,125 / 77$ and $108 / 62 \mathrm{mmHg}$, respectively) [10].

The present study confirmed that daytime ambulatory blood pressure was on average lower than the conventional blood pressure in hypertensive patients, whereas the opposite was observed in individuals who were normotensive on regular sphygmomanometry. In our study the conventional blood pressure compared with the daytime blood pressure was $5.7 / 0.1 \mathrm{mmHg}$ lower in 108 normotensive people, but $17.1 / 13.1 \mathrm{mmHg}$ higher in 54 hypertensive patients. A similar trend was also observed in the International Database of Ambulatory Blood Pressure Monitoring [5]. Observer bias and the white-coat effect [28-30] may explain why in hypertensive patients the blood pressure at the clinic was usually higher than the daytime ambulatory blood pressure. On the other hand, in the normotensive participants, the daytime ambulatory blood pressure was recorded during regular activities, when the blood pressure may rise slightly due to physical or psychological stress. Moreover, in normotensive people, the conven- 
Fig. 4

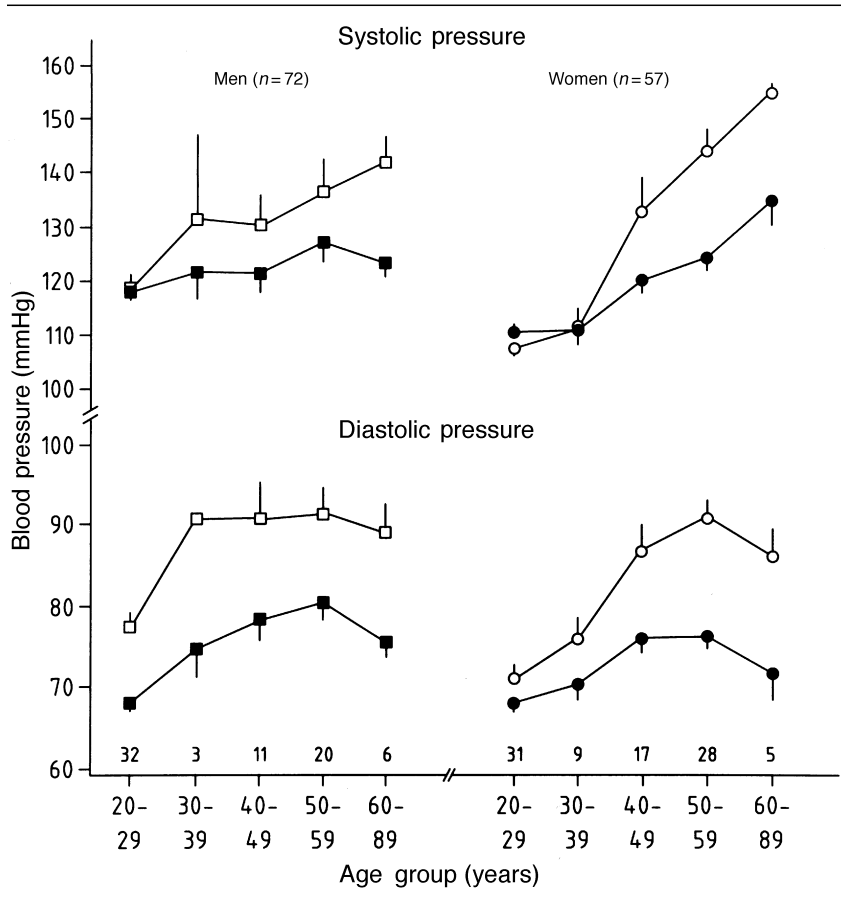

The conventionally measured blood pressure and the 24-h ambulatory blood pressure by age in men (squares) and women (circles). Values are means \pm SEM. Conventionally measured blood pressure (average of five readings at the clinic; $\circ, \square)$; 24-h ambulatory blood pressure

$(\bullet$ or $\boldsymbol{\square})$.

tional pressure may decrease by a few $\mathrm{mmHg}$, when measured in relaxed conditions after a few minutes rest in the sitting position.

In proposing operational thresholds for use in clinical practice, the present study should not be considered in isolation. In the normotensive participants enrolled in this study, the 95th percentiles were considered as the upper limits of normality for the 24-h, clocktime day and clocktime night blood pressures. These values were $128 / 81,136 / 86$ and $118 / 72 \mathrm{mmHg}$, respectively (Table 1). In previous analyses [10], averaging the 95th percentiles in normotensives and rounding the resulting boundaries downwards or upwards to the nearest value ending in 0 or 5 , produced working definitions of normality for ambulatory blood pressure monitoring, which can be easily remembered. Following the same procedure, the upper limits of normotension in the Novosibirsk population, would be values less than $130 / 80 \mathrm{mmHg}$ for the 24-h pressures and 135/85 and $120 / 70 \mathrm{mmHg}$ for the daytime and nighttime pressures. These preliminary threshold values for the population of Novosibirsk do not account for sex and age. However, in agreement with previous reports [7,9], the present data (Fig. 4) also confirmed that age is a much stronger correlate of the conventional than of the ambulatory blood pressure.

The present study has some limitations because it involved only 162 participants, of whom $33.3 \%$ were borderline or definitely hypertensive. Nevertheless, this first interim report, based on the Novosibirsk arm of the EPOGH study, attempted to describe the distribution of the ambulatory blood pressure measurements and to determine a preliminary threshold for ambulatory blood pressure monitoring in a random sample drawn from the population of Novosibirsk, Russia. In comparison with several large studies on ambulatory blood pressure monitoring $[2,5,10,15]$, the present interim report produced consistent results with respect to the distributions of the ambulatory measurements in the general population.

\section{Acknowledgements}

This investigation was conducted in the framework of the European Project on Genes in Hypertension (EPOGH), which is supported by the European Union (contract number ERB IC15-CT98-0329).

\section{References}

1 James GD, Moucha OP, Pickering TG. The normal hourly variation of blood pressure in women: average patterns and the effect of work stress. J Hum Hypertens 1991; 5:505-509.

2 O'Brien E, Murphy J, Tyndall A, Atkins N, Mee F, McCarthy G, et al. Twenty-four-hour ambulatory blood pressure in men and women aged 17 to 80 years: the Allied Irish Bank Study. J Hypertens 1991; 9:355360.

3 Staessen JA, Fagard RH, Lijnen PJ, Thijs L, Van Hoof R, Amery AK. Mean and range of the ambulatory blood pressure in normotensive subjects from a meta-analysis of 23 studies. Am J Cardiol 1991; 67:723-727

4 Thijs L, Amery A, Clement D, Cox J, De Cort P, Fagard R, et al. Ambulatory blood pressure monitoring in elderly patients with isolated systolic hypertension. J Hypertens 1992; 10:693-699.

5 Staessen JA, O'Brien ET, Amery AK, Atkins N, Baumgart P, De Cort P, et al. Ambulatory blood pressure in normotensive and hypertensive subjects: results from an international database. J Hypertens 1994; 12 (suppl 7):S1-S12.

6 Mancia G, Omboni S, Ravogli A, Parati G, Zanchetti A. Ambulatory blood pressure monitoring in the evaluation of antihypertensive treatment: additional information from a large data base. Blood Press 1995; 4:148-159.

7 Imai $Y$, Nagai K, Sakuma M, Sakuma $H$, Nakatsuka $H$, Satoh $H$, et al. Ambulatory blood pressure of adults in Ohasama, Japan. Hypertension 1993; 22:900-912.

8 Staessen J, Bulpitt CJ, O'Brien E, Cox J, Fagard R, Stanton A, et al. The diurnal blood pressure profile. A population study. Am J Hypertens 1992; 5:386-392.

9 Staessen J, O'Brien E, Atkins N, Bulpitt CJ, Cox J, Fagard R, et al. The increase in blood pressure with age and body mass index is overestimated by conventional sphygmomanometry. Am J Epidemiol 1992; 136:450-459.

10 Staessen JA, Bieniaszewski L, O'Brien ET, Imai Y, Fagard R. An epidemiological approach to ambulatory blood pressure monitoring: the Belgian population study. Blood Press Monit 1996; 1:13-26.

11 Imai Y, Munakata M, Hashimoto J, Minami N, Sakuma H, Watanabe N, et al. Age-specific characteristics of nocturnal blood pressure in a general population in a community of northern Japan. Am J Hypertens 1993; 6:179S-183S.

12 Sega G, Bravi C, Cesana G, Valagussa F, Mancia G, Zanchetti A. Ambulatory and home blood pressure normality: The Pamela Study. J Cardiovasc Pharmacol 1994; 23 (suppl 5):S12-S15. 
13 Cesana G, De Vito G, Ferrario M, Libretti A, Mancia G, Mocarelli P, et al. Ambulatory blood pressure normalcy: the PAMELA Study. J Hypertens 1991; 9 (suppl 3):S17-S23.

14 Zanchetti A. The physiologic relevance of smooth twenty-four-hour blood pressure control. J Hypertens 1995; 12 (suppl 2):S17-S23.

15 Wiinberg N, Hoegholm A, Christensen HR, Bang LE, Mikkelsen KL, Ebbe Nielsen $\mathrm{P}$, et al. 24-h ambulatory blood pressure in 352 normal Danish subjects, related to age and gender. Am J Hypertens 1995; 8:896-978.

16 Petrie JC, O'Brien ET, Littler WA, de Swiet M. Recommendations on blood pressure measurement by a working party of the British Hypertension Society. BMJ 1989; 293:611-615.

17 The Joint National Committee on Detection Evaluation and Treatment of High Blood Pressure. The Sixth Report of the Joint National Committee on Detection, Evaluation, and Treatment of High Blood Pressure (JNC VI). Arch Intern Med 1997; 157:2413-2446.

18 Guidelines Sub-Committee. 1999 Guidelines for the management of hypertension: memorandum from a World Health Organization / International Society of Hypertension meeting. J Hypertens 1999 17:151-83.

19 Groppelli A, Omboni S, Parati G, Mancia G. Evaluation of noninvasive blood pressure monitoring devices Spacelabs 90202 and 90207 versus resting and ambulatory 24-hour intra-arterial blood pressure. $\mathrm{Hy}$ pertension 1992; 20:227-232.

20 O'Brien E, Mee F, Atkins N, O'Malley K. Evaluation of the SpaceLabs 90202 non-invasive ambulatory recorder according to the AAMI Standard and BHS criteria. J Hum Hypertens 1991; 5:223-226.

21 Thijs L, Staessen J, Fagard R. Analysis of the diurnal blood pressure curve. High Blood Press Cardiovasc Prev 1992; 1:17-28.

22 van Ittersum FJ, ljzerman RG, Stehouwer CDA, Donker AJM. Analysis of twenty-four-hour ambulatory blood pressure monitoring: what time period to assess blood pressures during waking and sleeping. $J$ Hypertens 1995; 13:1053-1058.

23 Shapiro SS, Wilk MB. An analysis of variance test for normality (complete samples). Biometrika 1965; 52:591-611.

24 Snedecor GW, Cochran WG. Statistical Methods. 7th ed. Ames, lowa, USA: The lowa State University Press; 1980. pp. 64-82.

25 The SAS Institute Inc. The REG Procedure. In: SAS/STAT User's Guide, Version 6, Fourth Edition, Volume 2, GLM-VARCOMP. 4th edn. Cary, North Carolina, USA: SAS Institute; 1995. pp. 1350-1456.

26 Kleinbaum DG, Kupper LL, Muller KE. Applied Regression Analysis and Other Multivariate Methods. 2nd ed. Boston, Massachusetts, USA: PWS-Kent Publishing Company; 1988. pp. 41-95.

27 Gould BA. An Assessment of the Accuracy and Role of Self-Recorded Blood Pressure in the Management of Hypertension [thesis]. London, UK: Thesis submitted for the Doctorate of Medicine, University of London; 1983.

28 Hoegholm A, Kristensen KS, Madsen NH, Svendsen TL. White coat hypertension diagnosed by $24-h$ ambulatory monitoring. Examination of 159 newly diagnosed hypertensive patients. Am J Hypertens 1992; 5:64-70.

29 Pickering TG, James GD, Boddie C, Harshfield GA, Blank S, Laragh $\mathrm{JH}$. How common is white coat hypertension? JAMA 1988; 259:225228.

30 Mancia G, Bertinieri G, Grassi G, Parati G, Pomidossi G, Ferrari A, et al. Effects of blood pressure measurement by the doctor on patient's blood pressure and heart rate. Lancet 1983; ii:695-698. 